\title{
An Analysis of Non-English Majors' Translation Learning Concepts and Development Features
}

\author{
Hui Zhang ${ }^{1, a}$ * \\ ${ }^{1}$ The School of Foreign Languages, Hubei University of Science and Technology, Xianning, China \\ a zhanghui2013@163.com
}

Keywords: Non-English majors, translation learning concepts, features.

\begin{abstract}
For non-English majors, translation learning concepts have a very important role in the process of learning, which is one of the most important factors that help students improve their learning. This study explores the translation learning concepts and their development features of non-English majors. The results show that for non-English majors, the majority approves of translation strategies and disapprove of self-concepts in translation learning. There are five major factors influencing students' translation of learning concepts. In the process of English translation learning, students' concepts develop from the significant changes at the beginning to the later stability.
\end{abstract}

\section{Introduction}

With the development of cognitive science and constructivist teaching methods, learner factor has become the focus of teaching research. One of the important constitutes of learner factor is learning concepts. It refers to the knowledge of learners about learning essence, process, and information of the learner (including oneself) (Wenden 1999), a relatively stable knowledge system. However, as learners are incrementally mature in cognition, they usually adjust or develop new thoughts based on the original ideas. Wang Shuhuai and Li Changjiang (2008) have summarized two major deficiencies of traditional translation teaching research: one is attaching importance to "Materials" --- translation products, underrating "people" ---students; the other is lack of empirical research. In other words, the empirical study targeted on learners in the translation teaching is relatively few. Language teaching has been gradually abandoning the traditional teacher-centered method, turning to teaching model that focuses on cultivating communication skills. The success of teaching reform means that translation teaching must simultaneously emphasize the study of learner factor, and translators must fully understand and consider the subjective features of the translator, in which translation learning concepts is of vital importance. This paper tries to explore the translation learning concepts and their development features of non-English majors.

\section{Content}

There are two major problems to be solved. One is what non-English major's translation learning concepts are and its constituents; the other is what their development features on translation learning concepts.

\section{Method}

\subsection{Subject}

In the research, a questionnaire on the freshmen and sophomores of non-English majors was made in one of the local universities in Hubei province. From the data, the number of the valid questionnaires was 335, with the number of grade 1, grade 2 and grade 3 students is 100, 123and 112 , 
respectively, in which the proportion of male and female students is $73: 262$, the average age of the student's age is 20.6 years old.

\subsection{Instrument}

The survey of a questionnaire was applied in order to obtain the data from the test in the study. Before the survey, relevant questions in the questionnaire were made according to the language learning concepts questionnaire, in combination with teachers' own teaching experience, in terms of students' translation learning strategies and motivations. Afterwards, the contents of the questionnaire were modified by translation teachers to demonstrate learning concepts features of more students. Before the survey is conducted, the questionnaire needs to be inspected to ensure its reliability and authenticity. For the questionnaire, Likert Five Scaling Method was employed to accurately display the investigators' answers. The number of questions is 21 and the total score is 105 points, in which the score of each question is same. SPSS11.5 was used to analyze the survey results.

\section{Results}

\subsection{The Components of English Non-majors' Translation Learning Concepts}

\subsubsection{Descriptive statistical analysis}

Through the analysis of the questionnaire, we can know that students' translation learning concepts mainly focused on learning strategies and motivations for learning. The M-values of students in the survey for learning strategies and learning motivation are all 4.0, and the SD values are above 0.6, which indicates that these two learning concepts are highly approved by students. The survey result indicates that most of the students are affirmative for motivations and strategies for English translation learning, yet they have a negative attitude towards self-concepts and nature. For English translation study, students believe that the translation of vocabulary and cultural differences has a huge impact on the student's own learning, and many students think that social practice translation projects should be increased. The analysis of the survey results shows that in the process of teaching translation, teachers need to deepen and investigate students' own concepts and motivations to help students better understand the importance of learning concepts. In addition, social practice translation projects for students could be increased according to their needs, which might be able to promote students' learning interest and improve their English translation abilities.

\subsubsection{Factor analysis}

In order to be able to investigate students' translation learning concepts, the method of factor analysis was used to further analyze students' learning concepts. It includes four steps: To start with, the correlation between observation factors should be analyzed in order to observe whether it is suitable to be factors for analysis, and then appropriate observation variable load is calculated and analyzed, which is significant when it is up to or over 0.3.In addition, The factors are extracted and the principal component method is used to rotate and select factors. The last step is to name the factors. From the investigation of translation learning concepts factor which affects the non-English majors, it is found that the translation learning concepts is probably composed of 5 factors, which is as follows: Translation study self-concepts factor, motivation factor, intrinsic strategy factor and outer strategy factor and translational learning factor.

\subsection{The survey of the features of translation learning concepts development and maturity}

\subsubsection{The survey of the features of translation learning concepts development}

From the previous survey, it is found that for non-English majors in a local university, in terms of students' translation learning concepts, students relatively highly accepted learning strategy and motivation. The simple study of the features of translation learning concepts development was conducted to have an overall knowledge of the undergraduates' English translation learning concepts. 
In the study, independent variable was grade. The survey was targeted to 3 different grades of students and their translation learning concepts for investigation and analysis. Through a single factor differential analysis method, we can know that there are much obvious differences English learning concepts between different grade.

\subsubsection{Study on differences in translation concepts among students of different grades}

The statistical data of learning concepts among university students in different grades show that for students' translation learning concepts, they are most positive in grade 1 since that they do not understand the specific learning content. With students went into further grade, their understanding of English translation learning has gradually deepened, and enthusiasm of students has fallen significantly. This is because students have come across a huge gap between English translation learning and actual learning. As a result, students’ learning enthusiasm has been severely hit.

\subsubsection{Factors affecting differences in translation learning concepts among different grades of students}

It can be known from the investigation that the students in the study have already taken a large number of translation exercises when they are studying in the grade 2. Although there is no translation teaching course, there are some related exercises in student's regular learning, so the enthusiasm of translation learning of that stage is also changing.

Therefore, when English translation is taught for non-English majors in the university, the following measures can be taken to improve students' enthusiasm: To begin with, when students in grade 1 and 2 select teaching materials, they may try to put away the teaching materials of translation exercises as much as possible, so as to avoid students excessively early take translation exercises. Because the students in this stage mainly study the basic knowledge, the teacher will not guide the student's learning concepts at this stage of the teaching. Too many translation exercises will cause the students to form the wrong learning concepts and make negative effect on student's follow-up learning. However, if some sentence translation is properly conducted in the teaching process, student's academic performance will increase to a higher degree, and students will be better in translation. Therefore, some simple and student-acceptable translation exercises could be chosen in the teaching process.

\section{Conclusion}

The results show that as to the translation learning concepts, students mainly approved of learning strategies and motivations, while the self-concepts and other aspects are poorly identified, which have a great impact on student's learning effect. There are 5 factors which influences students' translation learning concepts. Only if every factor could favor students' correct translation learning concepts establishment that learning results would be better. Therefore, a comprehensive analysis of the students could be implemented in English translation teaching and some experienced teachers could be chosen to teach students.

\section{Acknowledgement}

This research was financially supported by the Teaching Research Funds for Hubei University of Science and Technology (Grant NO.2014-XB-006).

\section{References}

[1] Bialystok E, (1981), The role of conscious strategies in second language proficiency, The Modern Language Journal, 65, 24 -35.

[2] Horwitz E K, (1988), The beliefs about language learning of beginning university foreign language students, The Modern Language Journal, 72, 283-294. 
[3] Nunan D, (1987), Communicative language teaching: making it work, English Language Teaching Journal, 41, 136-145.

[4] Wang Shuhuai, and Li Changjiang, (2008), China translation teaching research: development, question and methods, Foreign Language World, 2, 27-33.

[5] Wenden A, (1999) An introduction to metacognitive knowledge and beliefs in language learning: Beyond the basics, System, 27, 435-441. 